\title{
Chapter 17 \\ What to Do with Unwanted Catches: \\ Valorisation Options and Selection \\ Strategies
}

\author{
Bruno Iñarra, Carlos Bald, Marta Cebrián, Luis T. Antelo, \\ Amaya Franco-Uría, José Antonio Vázquez, Ricardo I. Pérez-Martín, \\ and Jaime Zufía
}

\begin{abstract}
The European Common Fisheries Policy (CFP) has established a landing obligation (LO) and the need for proper management of bycatches without incentivising their capture. Food use is the priority option but only unwanted catches (UWC) above minimum conservation reference size (MCRS) can be used for direct human consumption. As a result, other options, such as animal feeds, industrial uses or energy, should be considered to valorise landed $<$ MCRS individuals. Two approaches have been developed to help select the best available option for processing UWC. The first methodology is based on a multi-criteria decision analysis (MCDA) using an analytic hierarchy process (AHP) that considers technical, economic and market criteria. As a sample case, we chose the Basque fleet fishing in the Bay of Biscay, developed within the H2020 DiscardLess project. The second approach is based on the simultaneous analysis of both economic and environmental aspects. This was applied to the case of Spanish bottom trawlers operating in ICES sub-Divisions VIIIc and IXa. Finally, various food products and bio compounds from typical UWC biomass were obtained in a pilot food processing plant developed within the LIFE iSEAS project.
\end{abstract}

B. Iñarra $(\bowtie) \cdot C$. Bald $\cdot$ M. Cebrián $\cdot$ J. Zufía

AZTI, Efficient and Sustainable Processes area, Parque Tecnológico de Bizkaia, Derio, BI, Spain

e-mail: binarra@azti.es

L. T. Antelo · J. A. Vázquez · R. I. Pérez-Martín

Marine Research Institute IIM-CSIC, Vigo, Spain

\footnotetext{
A. Franco-Uría

Department of Chemical Engineering, School of Engineering, University of Santiago de Compostela, Santiago de Compostela, Spain
} 
Keywords $\varepsilon$-constraint approach · Analytic hierarchy process - Biomolecules · Biorefinery $\cdot$ Bycatches $\cdot$ Discards management $\cdot$ In-land management $\cdot$ Landing obligation $\cdot$ Multi-criteria decision analysis $\cdot$ Unwanted catches $\cdot$ Valorisation

\subsection{Introduction}

In 2013, the European Commission introduced a Landing Obligation (LO) or 'discard ban' which stated that all catches of species subject to catch quotas and/or minimum conservation reference size (MCRS) must be landed and will be counted against quota. The LO is being gradually implemented from 2015 to 2019 for all regulated species across the EU. In the meantime, various strategies are needed to mitigate any potential negative impacts of the $\mathrm{LO}$ on fishing-dependent industries and communities.

Even after implementation of strategies to reduce bycatches a fraction of unwanted catches (UWC) may still be caught and will have to be landed. These UWC may not be used or sold for human consumption, thus other appropriate valorisation options are needed.

When choosing the most suitable use of UWC, one must first consider the reason for discarding these fractions. For those UWC that are $>$ MCRS and of adequate quality for direct marketing, but which were discarded due to lack of fresh market demand, new (transformed) food products must be developed to prevent flooding the fresh fish market. For those UWC > MCRS of insufficient quality for human consumption or for UWC < MCRS, whose use for direct human consumption is forbidden by LO, a wide range of available technological alternatives exist. Not all of them may be equally feasible, however.

The Waste Framework Directive of the EU Parliament (2008) (Fig. 17.1) has established a hierarchy of management options for any food waste or by-product. The preferred choice is always prevention and reduction. In the case of fisheries discards, this is represented by reduction of bycatches via increased gear selectivity and optimisation of fishing strategies (see e.g. O'Neill et al., this volume; Reid et al., this volume). Second, the food by-product should be kept in the food chain as either fresh fish or transformed products (subject to legislation) or by the production of food ingredients. Third, bio-products (i.e., valuable compounds or biomolecules for food, cosmetic or other uses) should be obtained if possible. Fourth is the production of feed for aquaculture, pet-food and other animal feeds. The production of fishmeal is the most common use of fish by-products, used mainly for aquaculture, and is a straightforward option for the treatment of UWC if a fishmeal plant is located nearby.

Other lower-value options can also be imagined and evaluated, such as products for industrial uses, the production of energy, composting or incineration. A final option, putting UWC in a landfill, is not considered a valorisation option. 


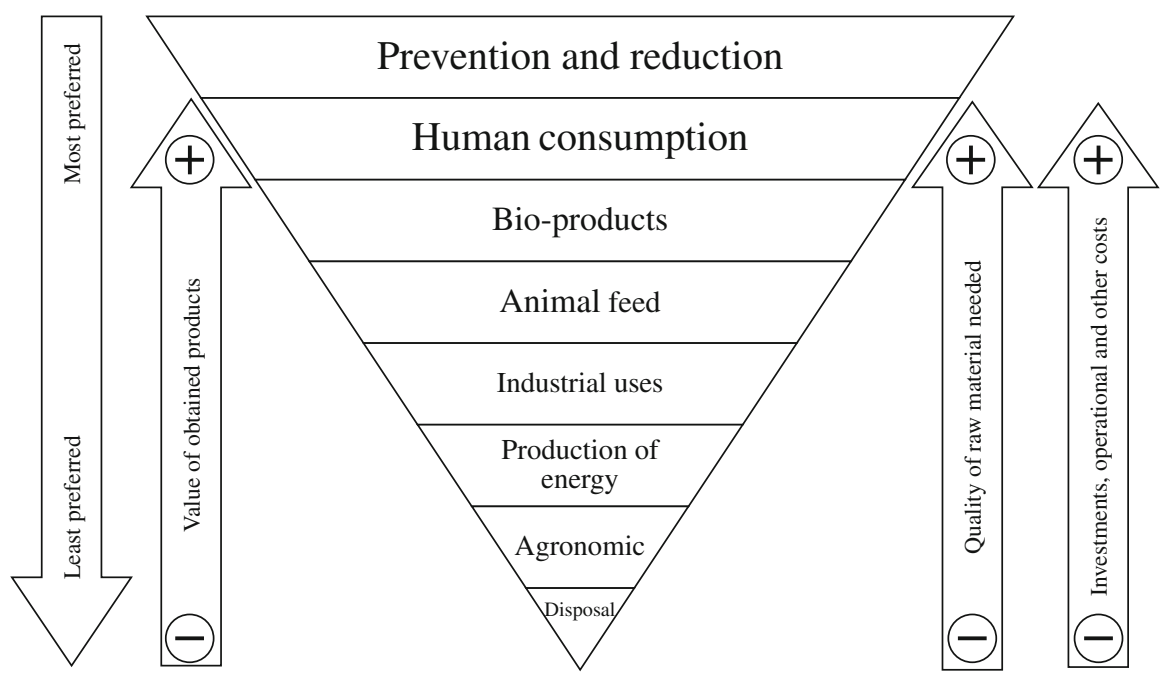

Fig. 17.1 Fish waste management hierarchy adapted from the European waste framework directive and the United States Environmental Protection Agency

To select the most suitable valorisation solution in a specific scenario, many criteria must be considered at the same time. This complicated task requires a suitable systematic methodology. All aspects that may determine the feasibility of a valorisation option can be classified into four main categories:

1. Characteristics of raw material which determine logistics needs and potential end products:

- Variability, seasonality and geographic dispersion of landings

- Physicochemical and microbiological characteristics of landed catches

2. Technical parameters, related to the technical feasibility of a solution, such as:

- Maturity of the production process

- Ratio, quality and purity of the product obtained

- Availability of technology and equipment at an industrial scale

- Feasibility of modifications on board vessels

- Availability of shore-based facilities for storage, preservation, logistics, and processing

3. Market aspects that affect product characteristics and their marketability:

- Compliance with health, environmental and other specific regulations for each use

- Existence of potential users or market acceptance for new products

- Existence of a gap in the market or of demand for an existing product

- Competitors and analogues

- Quality requirements and volume of available product to satisfy demand 
4. Economic aspects are the factors that affect the economic feasibility of the solution such as:

- Minimum volume of raw material for viable production

- Final value / price of product

- Expected cost-benefit ratio

- Efficient use of existing infrastructures

In many cases, it is almost impossible to collect all the information needed to evaluate all the options, and feasibility studies are quite expensive and time consuming. Instead, we first identify more than 30 products from valorisation options in this chapter. Two methodologies for the selection of valorisation options have been developed with the aim of creating a common, systematic and objective pathway for addressing the decision process.

\subsection{Potential Uses of Unwanted Catches}

Existing valorisation options and their resulting products were reviewed and compiled. Then, following the waste management hierarchy (Fig. 17.1), these products were classified as follows: food applications, bio-products, animal feed, industrial uses, energy production or agronomic uses (Table 17.1). This prioritisation does not refer to the value of the product, as different markets or uses can strongly affect value.

There is a global trend towards increased demand for fish for human consumption compared to other uses. Fish protein contributes an average $17 \%$ of the total animal protein intake globally and in some countries up to 23\% (FAO 2017). For UWC > MCRS, there are many solutions in the area of food product innovation. Global consumer trends in industrialised countries show opportunities for new product developments in the categories of processed and ready-to-eat food. Fish pulp, obtained from fish muscle as a basis for making restructured products or surimi derivatives, are intermediate products that can be good options when a critical mass is available and the freshness of the raw material is guaranteed.

When UWC cannot be used for direct human consumption, there are many alternative uses that are gaining in importance and may lead to important revenue streams. A brief description is given below, and more detailed data sheets can be found in Iñarra et al. (2018).

Seafood contains a variety of high-value biomolecules that can be used in food, pharmaceuticals and cosmetics, such as in the animal feed industry (pet food, aquaculture and cattle).

1. Bioactive Peptides: come from the extensive enzymatic hydrolysis of fish protein. They present biological activities, such as antihypertensive, antibacterial, anticoagulant, anti-inflammatory or antioxidants, which make them valuable for food, pharmaceuticals, cosmetics and feed products. 
Table 17.1 Main valorisation options of unwanted catches by product category

\begin{tabular}{|c|c|}
\hline Category & Valorisation option \\
\hline \multirow[t]{3}{*}{ Food Applications } & New fish products \\
\hline & Surimi \\
\hline & Fish pulp \\
\hline \multirow[t]{17}{*}{ Bio-products } & Bioactive peptides \\
\hline & Polyunsaturated fatty acids \\
\hline & Enzymes \\
\hline & Chondroitin sulphate \\
\hline & Fat-soluble vitamins \\
\hline & Minerals \\
\hline & Astaxanthin \\
\hline & Collagen \\
\hline & Gelatine \\
\hline & Sterols \\
\hline & Insulin \\
\hline & Protamine \\
\hline & Hyaluronic acid \\
\hline & Chitin/chitosan \\
\hline & Phospholipids \\
\hline & Peptone \\
\hline & Squalene \\
\hline \multirow[t]{9}{*}{ Animal feed } & Fishmeal \\
\hline & Fish oil \\
\hline & Mink feed \\
\hline & Marine beef/bait \\
\hline & Direct pig feed \\
\hline & Protein concentrate \\
\hline & Protein hydrolysate \\
\hline & Silage \\
\hline & Insects growth medium \\
\hline \multirow[t]{5}{*}{ Industrial uses } & Leather \\
\hline & Fish oil \\
\hline & Minerals \\
\hline & Chitin/chitosan \\
\hline & Pearl essence \\
\hline \multirow{2}{*}{ Energy } & Biogas \\
\hline & Biodiesel \\
\hline \multirow[t]{2}{*}{ Agronomic uses } & Fertilisers \\
\hline & Compost \\
\hline
\end{tabular}

2. Polyunsaturated fatty acids (PUFAs): come from the purification of fish oil, obtained from viscera or from fatty fishes, and are fats with more than one unsaturation (double bonds) present in their chain. PUFAs include important compounds such as essential fatty acids that are correlated with human cardiovascular health. 
3. Proteases and proteolytic enzymes: are extracted from by-products, especially viscera, that contain a substantial proportion of digestive enzymes, with different specific functions. These include collagenases, trypsin, pepsin, chymotrypsin, elastase, and carboxypeptidase. These enzymes extracted from fish are active at low temperature and $\mathrm{pH}$. Proteases play a key role in a wide variety of physiological processes, biotechnology, food processing and other industries.

4. Chondroitin sulphate: is obtained by an enzymatic or chemical hydrolysis process to deproteinise cartilage phases from the skeleton of cartilaginous fish, sharks and rays, followed by successive purification steps. Chondroitin sulphate gives cartilage its mechanical and elastic properties and gives it a large part of its resistance to compression. Chondroitin sulphate is used as a dietary supplement with anti-inflammatory properties, to ease arthritis symptoms.

5. Fat-soluble vitamins: are obtained by solvent extraction of vitamins from fish oil. Vitamins are classified as either fat soluble (vitamins A, D, E and K) or water soluble (vitamins B and C) depending on how they act within the body. Fish liver oil, rich in vitamins A and D, is used in pharmaceutical, cosmetic and food applications.

6. Minerals (Calcium, $\mathrm{CaCO}_{3}$, hydroxyapatite): are obtained from fish bones and shells of bivalve molluscs (mussels, clams, etc.). They can be used as mineral supplements in nutraceutical products (for human or animals) as food ingredient and in technically lower value applications such as soil improvers or mineral fertilisers.

7. Dye/pigments (Astaxanthin): is extracted mainly from crustacean shells. It is used as a pigment in aquaculture, in fish and crustacean feed and as antioxidant in nutraceutical formulations.

8. Collagen: is obtained by an acid or base treatment of spines, scales and skin. The amino acid content of collagen differs from other proteins because of their high content of proline and hydroxyproline. Collagen is widely used in the pharmaceutical and cosmetic industries and as food supplement.

9. Gelatine: is obtained from the partial hydrolysis of collagen. There are two main types of gelatines: Type A is obtained from the acid hydrolysis procedure and Type B from the alkaline hydrolysis procedure. Gelatine is used as gelling agent in food, pharmaceuticals and cosmetics. Fish gelatines are preferred for low temperature gelling needs.

10. Sterols: are obtained from either plants or animals. Phytosterols, which have received considerable attention in recent years due to their cholesterol-reducing properties, can be found in marine organisms whose diet is mainly made up of phytoplankton. An important source of phytosterols is bivalves (filtering organisms). Phytosterols are increasingly demanded as functional ingredients in the food and beverage industry.

11. Insulin: is extracted from the viscera of various fish. Insulin is a peptide hormone produced by beta cells of the pancreatic islets, and by the Brockmann body in some teleost fish. Insulin regulates the amount of glucose (sugar) in the blood and is required for the body to function normally. It is used for treating diabetes. 
12. Protamine: is a purified mixture of simple proteins obtained mainly from wild salmon sperm. Protamine is a protein (molecular weight around 4-5 kDa) which works to maintain and protect DNA from being damaged. It is used in pharmaceuticals as a drug that reverses the anticoagulant effects of heparin by binding to it.

13. Hyaluronic acid: is a glycosaminoglycan present in skin, bones and joints. It is obtained by successive extraction and purification steps. Its function is to give elasticity to skin, bones and joints. It is used in regenerative skin cosmetics, in cosmetic surgery injections or in the recovery of joint injuries.

14. Chitin/Chitosan: Chitin is obtained by deproteinisation and discoloration of the exoskeleton of arthropods. Chitosan is obtained by further deacetylation of chitin by chemical-enzymatic processes. Chitosan, in various modified forms and different degrees of purity, can be used in a wide range of applications. It is used in food applications, in edible films or in microencapsulation of ingredients; in pharmaceuticals, in nutritional supplements as fat binder; in aquaculture and ruminant feeding to reduce infections and improve yield; in medicine as material in histocompatible tissues and contact lenses; and in cosmetics in foams. One of its main applications is as a food-grade flocculant in water treatment and in paper manufacturing.

15. Phospholipids (PLs): are extracted from fish oil using different procedures. Marine PLs contain essential omega-3 PUFAs, some of which are only present in marine sources. PLs are used as emulsifiers in the food industry, or as emollients in cosmetics, antibacterials or in drug delivery.

16. Squalene: is extracted mainly from shark liver. A hydrocarbon compound, isoprenoid, is intermediate in the synthesis of cholesterol, hormones and vitamin D. It is used in cosmetics as a lubricant and in pharmacy or dietary supplements as an immunostimulator.

17. Peptones: are produced by controlled enzymatic hydrolysis of proteins. Peptones are a mixture of polypeptides and amino acids formed during the enzymatic degradation of proteins. They are the main source of nitrogen in the organic media for bacterial culture. They are used in the manufacture of culture media for microbiology and biotechnology (industrial fermentations).

The most common use of fish by-products is the production of fishmeal and fish oil that is mainly used for animal feed. This alternative may also be of major interest for the processing of UWC as there are many infrastructures available that are generally close to harbours. However, many other valorisation options focused on animal feed can be considered.

18. Fishmeal: is obtained from any fish or fish by-products. After a thermal process to coagulate the protein and separate the oil, fishmeal is a brown powder rich in protein. The colour is affected by the fish species, particle size, fat and moisture content. Fishmeal is mainly used in animal feed with aquaculture consumption accounting for $>60 \%$, pigs $25 \%$, and poultry $8 \%$.

19. Fish oil: is obtained in the same process as fishmeal production. Fish oil is a liquid product composed mainly of fatty acids that are highly unsaturated, with 
variable amounts of phospholipids, glycerol ethers and wax esters. Fish oil has different uses that can vary depending on its composition. About $80 \%$ of fish oil is used in aquaculture and $\sim 13 \%$ is destined for human consumption. When it does not meet feed quality standards it can be used in technical applications as solvent for painting or in biodiesel production.

20. Protein concentrates: Are dehydrated and ground products with a variable protein content, which may or may not taste or smell of fish, depending on the production method used. The aim is to achieve a stable product with a protein concentration higher than that of fish muscle. This type of product can use species that are not appropriate for direct consumption as well as the waste from fish processing industries. These concentrates are used for animal feed but due to their high nutritional value they can also be used for human consumption or as a protein source in the elaboration of different foods.

21. Protein hydrolysates: are prepared from the protein fraction of whole fish, by-products or processing waters. Hydrolysates are produced by chemical or enzymatic hydrolysis and consist of mixtures of amino acids and peptides (fragments of protein) of varying sizes depending on the degree of hydrolysis. Protein hydrolysates provide different technological properties such as flavouring or texturising agents. Their biological activities are also being studied scientifically.

22. Silage: Is a liquid protein hydrolysate made from whole fish or from processed residues. The hydrolysis is carried out by endogenous proteolytic enzymes located in the viscera and in the meat of the fish under acidic conditions. Acid conditions limit the growth of degradative bacteria. It is used mainly as a protein supplement in animal feed (cattle, poultry and aquaculture) and as a base to produce fish sauce.

23. Mink feed: any fish or fish by-product can be used to feed mink for the fur industry.

24. Marine bait: discarded species can be used as effective pot bait in the crab fishery.

25. Insect meal and oil: are obtained after rearing insects on a fish substrate to increase protein content. Insect meal can be used for animal feed.

At the bottom of the valorisation hierarchy are other technical options such as energy production and agronomic uses:

26. Pearl essence: is extracted from fish scales. Guanine is an iridescent substance that is found in the epidermal layer and scales. The suspension of guanine in a solvent is called "essence of pearls". It was formerly used in cosmetics and paints.

27. Fish leather: is the cured and tanned skins of fish. Fish leather can be used to make a wide variety of items such as jewellery, accessories, belts, wallets, bags and in shoes. It can also be used for a wide variety of crafts.

28. Biogas: is produced through the anaerobic digestion of organic matter. This is a complex biological process in which anaerobic bacteria decompose organic matter in environments with little or no oxygen. The process produces biogas (55-65\% methane, 35-45\% carbon dioxide, and other gases) used as energetic 


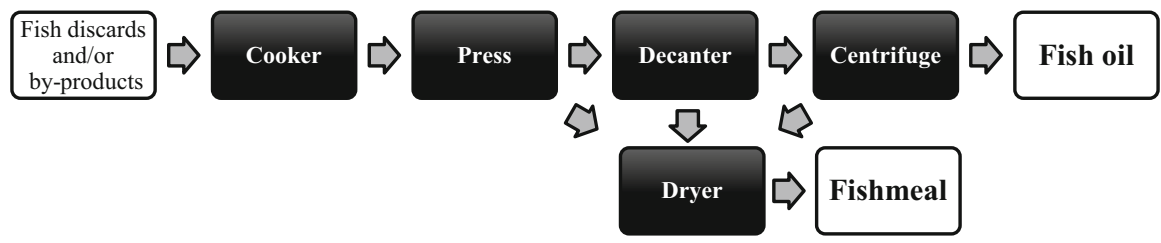

Fig. 17.2 Simplified stepwise schema of a fishmeal and oil production process

source for heating or producing electricity. A digested substrate is produced that can be used as fertilizer.

29. Compost/fertilisers: are obtained by an aerobic decomposition process carried out by the microorganisms of the organic matter. Compost made from fish usually consists of fish waste, sawdust, wood-bark chips and is covered with leaf compost to make a compost pile. The compost is used as a soil amendment or fertiliser. Fish protein hydrolysates can also be used as fertiliser.

Many of these processes of UWC valorisation can be run concurrently in a biorefinery scheme. For instance, when producing a food product, a first biorefinery step takes place when fish meat is separated from viscera, heads and bones. The latter can then be further processed to obtain other valuable products. Biorefinery is the integrated sustainable process that transforms a biological raw material (animal or plant material) into a spectrum of marketable products (e.g. food, feed, materials or chemicals) or energy (e.g. fuels, power and heat).

The simplest biorefinery scheme is to obtain fishmeal and fish oil where, when using a good stickwater recovery system, all the treated raw material provides marketable products. A simplified processing scheme is shown in Fig. 17.2. In brief, the raw material (UWC or fish by-product) is thermally treated and coagulated protein and oil are then separated and recovered.

\subsection{Simplified Methodology for the Selection of Potential Uses}

The methodology for the selection of the potential uses for UWC in a specific scenario has been developed within the H2020 DiscardLess project (Grant Agreement $n^{\circ} 633,680$ ) and is based on a multi-criteria decision analysis (MCDA) using an analytic hierarchy process (AHP) method. MCDA provides a reliable framework for procedures to rank alternative options and prioritise, based on their assessment across selected criteria, and such methods have been widely and effectively applied in different environmental areas (San Martin et al. 2017).

AHP was introduced as the most appropriate method, because it allows the problem to be partitioned into smaller decision sets that are addressed one at a time. The first step is to define and evaluate the criteria, which must be done case by case, as it is adapted to the subject of the study and stated by consensus. 
Table 17.2 Categories and Criteria for the MCDA

\begin{tabular}{l|l|l}
\hline Category & Criteria & Units \\
\hline \multirow{3}{*}{ CS dependent } & A: Available raw material & $\mathrm{T} /$ year \\
\cline { 2 - 3 } & B: Available facilities & $\mathrm{N}^{\circ}$ facilities \\
\hline \multirow{2}{*}{ Economic factors } & C: Yield & $\%$ \\
\cline { 2 - 3 } & D: Technology maturity & \\
\cline { 2 - 3 } & E: Value of the product & $€ / \mathrm{kg}$ \\
\cline { 2 - 3 } & F: Potential market & $\mathrm{Kg} /$ year \\
\cline { 2 - 3 } & G: Production costs & $€ / \mathrm{kg}$ \\
\cline { 2 - 3 } & H: Competing companies & $\mathrm{Kg} /$ year \\
\hline
\end{tabular}

Principles applied to the selection criteria to evaluate the main parameters involved in the process are:

- systemic principle: a criteria system should reflect the essential characteristic and the whole performance system

- measurability principle: the criteria should be measurable in quantitative values or qualitative criteria should be transformed into numbers

- comparability principle: criteria must be either comparable or normalised.

For the final evaluation, the selected criteria have been divided into three groups: Case Study (CS) dependent, technical and economic criteria (Table 17.2).

"Available raw material" is the amount of UWC that can be processed in this way.

The existence of "available facilities" and local infrastructures in the region should be positive.

"Yield" criteria represent the result of the proportion of fish that can enter this valorisation option as well as the yield of the process for the production of the valuable compound or final product.

"Technology maturity" refers to the industrial feasibility and necessary investment cost for implementing the solution. Maturity generally implies technical feasibility (availability of the technology) and lower implementation costs.

"Value of the product" stands for the market value of the product or compound.

"Potential market" is an indicator of demand for the product to be marketed.

"Production costs" account for the different costs involved in the production of the product.

"Competing companies" reflects the quantities produced or the size of the competitor companies.

The methodology has four main steps:

1. Data gathering for each valorisation option (including new options when identified)

2. Evaluate the facilities available for each option

3. Evaluate the amount of UWC available for each option

4. Complete the evaluation and prioritisation table 
For the first step - data gathering for each valorisation option - an exhaustive list of valorisation options according to the end-product have been assembled in a single sheet that allows a preliminary evaluation of the proposed solutions to be obtained (Iñarra et al. 2018). Further available options can be added to this list and can be weighted during the evaluation.

Second, the evaluation of existing and available facilities is carefully done in each case study. The selection of an option that is already industrialised has a great advantage and can be a straightforward and short-term solution.

Third, historical discard data or UWC landing data are used to determine and evaluate the amount of raw material available for each option. When using historical discard data, a careful evaluation becomes essential. It cannot be supposed that $100 \%$ of discards will be landed due to selectivity gear improvement, better fishing strategies or minimal applications.

After estimating the amount of UWC landed and considering the species and quality, the amount of raw material for each option can also be estimated, keeping in mind that catches under minimum conservation reference size (MCRS) cannot be used for direct human consumption.

A table linking the species with their possible valorisation options has been made (Iñarra et al. 2018). Table 17.3 shows the part of that table used for the Bay of Biscay case study (for details, see Sect. 17.5.1). The selected options are based on the species composition (Froese and Pauly 2018).

The quantitative values obtained in the first step of the methodology for each evaluation criterion and for all the valorisation options are then evaluated jointly. Subsequently, average ranges are established to define different levels for each criterion prioritisation (Table 17.4). Each range is then assigned a score. The more favourable the evaluation, the higher the score (Table 17.5); this is usually 5, 3, 1 and 0 . This allows small differences to be highlighted in following calculations. Considerations are that some factors have a negative effect (competing companies and production costs) and therefore have a high qualitative factor if their quantitative factor is low.

A weighting coefficient has been assigned to each prioritisation criterion and each valorisation option will obtain a score (a value between zero and one) based on the following equations:

$$
\begin{gathered}
\mathrm{V}_{\mathrm{CS}}=\left(\mathrm{x}_{1} \cdot \mathrm{A}+\mathrm{x}_{2} \cdot \mathrm{B}\right) /\left(5 \cdot\left(\mathrm{x}_{1}+\mathrm{x}_{2}\right)\right) \\
\mathrm{V}_{\text {tech }}=\left(\mathrm{x}_{3} \cdot \mathrm{C}+\mathrm{x}_{4} \cdot \mathrm{D}\right) /\left(5 \cdot\left(\mathrm{x}_{3}+\mathrm{x}_{4}\right)\right) \\
\mathrm{V}_{\text {eco }}=\left(\mathrm{x}_{5} \cdot \mathrm{E}+\mathrm{x}_{6} \cdot \mathrm{F}+\mathrm{x}_{7} \cdot \mathrm{G}+\mathrm{x}_{8} \cdot \mathrm{H}\right) /\left(5 \cdot\left(\mathrm{x}_{5}+\mathrm{x}_{6}+\mathrm{x}_{7}+\mathrm{x}_{8}\right)\right)
\end{gathered}
$$

Where $\mathrm{V}_{\mathrm{CS}}$ is the score obtained for the case study-dependent criteria, $\mathrm{V}_{\text {tech }}$ is the score of the technical criteria and $\mathrm{V}_{\mathrm{eco}}$ is the score of the economic criteria. $\mathrm{x}_{1}$ to $\mathrm{x}_{8}$ are the weighting coefficient values assigned to each criterion for the prioritisation and A, B, C, D, E, F, G, the score normalised from 0 to 5 for each criterion as shown in Table 17.5. 


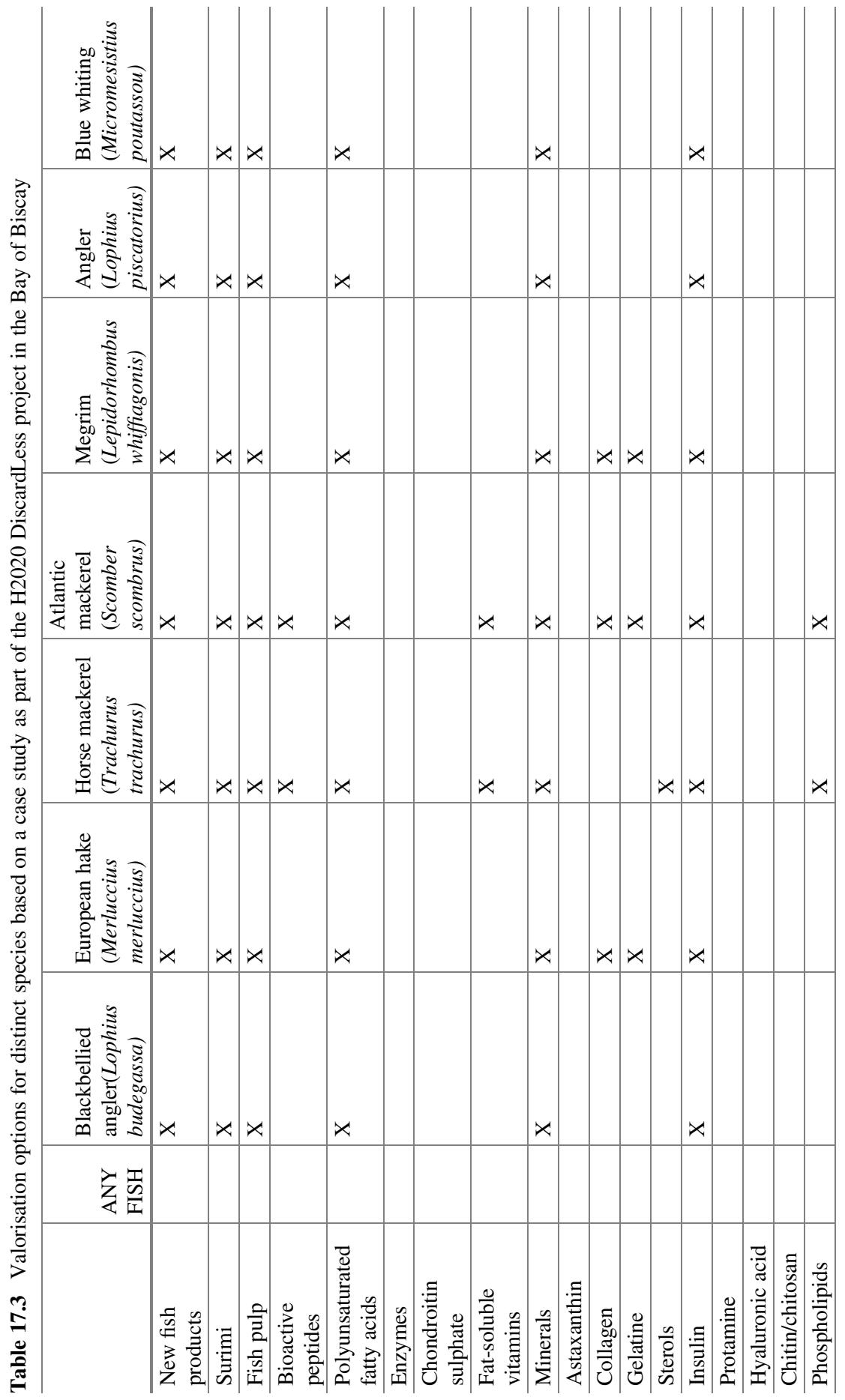


17 What to Do with Unwanted Catches: Valorisation Options and Selection Strategies

345

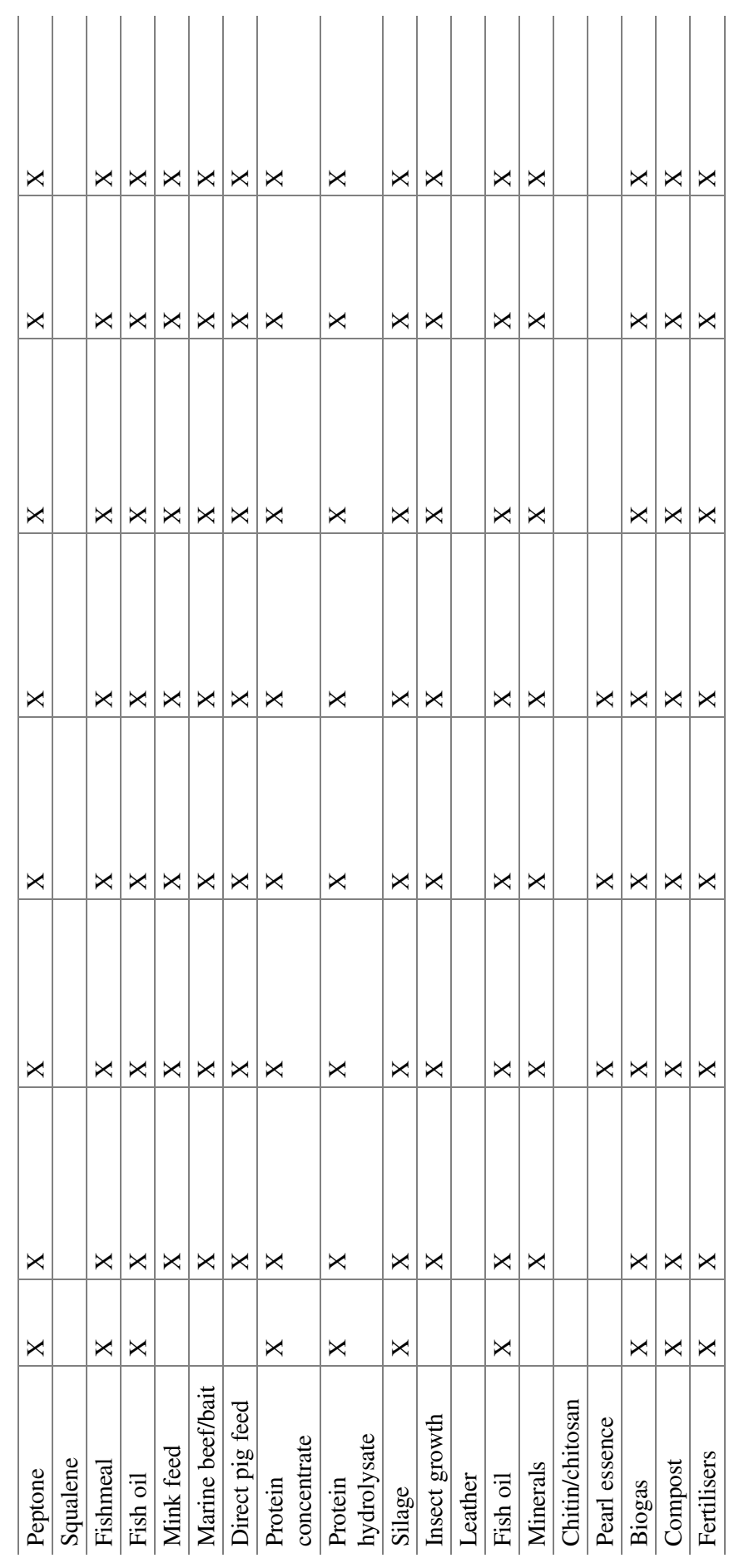


Table 17.4 Normalisation of range values of prioritisation criteria

\begin{tabular}{l|l|l|l|l|l|l}
\hline Category & Criteria & Units & High & Medium & Low & Null \\
\hline $\begin{array}{l}\text { Case study } \\
\text { dependent }\end{array}$ & $\begin{array}{l}\text { A: Available } \\
\text { raw material }\end{array}$ & t/year & $>2000$ & $1000-2000$ & $500-1000$ & $<500$ \\
\hline & $\begin{array}{l}\text { B: Available } \\
\text { facilities }\end{array}$ & $\begin{array}{l}\mathrm{N}^{\circ} \\
\text { facilities }\end{array}$ & $>2$ & 2 & 1 & 0 \\
\hline Technical & C: Yield & $\%$ & $>50$ & $10-50$ & $<10$ & $<0.05$ \\
\hline $\begin{array}{l}\text { D: Technology } \\
\text { maturity }\end{array}$ & - & High & Medium & Low & Experimental \\
\hline & $\begin{array}{l}\text { E: Value of } \\
\text { the product }\end{array}$ & $€ / \mathrm{kg}$ & $>50$ & $5-50$ & $0.5-5$ & $<0.5$ \\
\hline $\begin{array}{l}\text { F: Potential } \\
\text { market }\end{array}$ & $\mathrm{t} / \mathrm{year}$ & $>1000$ & $100-1000$ & $5-100$ & $<5$ \\
\hline & $\begin{array}{l}\text { G: Production } \\
\text { costs }\end{array}$ & $€ / \mathrm{kg}$ & $>50$ & $5-50$ & $0.5-5$ & $<0.5$ \\
\hline & $\begin{array}{l}\text { H: Competing } \\
\text { companies }\end{array}$ & $\mathrm{t} / \mathrm{year}$ & $>500$ & $100-500$ & $<100$ & 0 \\
\hline
\end{tabular}

Table 17.5 Assignment of numerical scores to each value range

\begin{tabular}{|c|c|c|c|c|c|}
\hline Category & Criteria & 5 & 3 & 1 & 0 \\
\hline \multirow[t]{2}{*}{$\begin{array}{l}\text { Case study } \\
\text { dependent }\end{array}$} & $\begin{array}{l}\text { A: Available } \\
\text { raw material }\end{array}$ & High & Medium & Low & Null \\
\hline & $\begin{array}{l}\text { B: Available } \\
\text { facilities }\end{array}$ & $\begin{array}{l}\text { Many } \\
\text { and/or } \\
\text { nearby }\end{array}$ & $\begin{array}{l}\text { Not many } \\
\text { and/or far } \\
\text { away }\end{array}$ & $\begin{array}{l}\text { Experimental } \\
\text { and/or pilot }\end{array}$ & Null \\
\hline \multirow[t]{2}{*}{ Technical } & C: Yield & High & Medium & Low & Null \\
\hline & $\begin{array}{l}\text { D: Technology } \\
\text { maturity }\end{array}$ & High & Medium & Low & Experimental \\
\hline \multirow[t]{4}{*}{ Economic } & $\begin{array}{l}\text { E: Value of the } \\
\text { product }\end{array}$ & High & Medium & Low & Null \\
\hline & $\begin{array}{l}\text { F: Potential } \\
\text { market }\end{array}$ & Big & Medium & Small & Null \\
\hline & $\begin{array}{l}\text { G: Production } \\
\text { costs }\end{array}$ & Very low & Low & Medium & High \\
\hline & $\begin{array}{l}\text { H: Competing } \\
\text { companies }\end{array}$ & Low-none & Medium & High & Saturated \\
\hline
\end{tabular}

Weighting coefficient values, $\mathrm{x}_{1}$ to $\mathrm{x}_{8}$ (Table 17.6) should highlight the importance of each criterion in the final decision and are usually values between 1 and 10:

- Key/critical factor: 10 points

- Very important factor: 7 points

- Factor with some relevance: 3 points

- Factor with small relevance: 1 point

The final score or priority value $\left(\mathrm{V}_{\mathrm{p}}\right)$ for each solution comes from the product of the technical and economical score. 
Table 17.6 Prioritisation evaluation of valorisation options for the Bay of Biscay case study

\begin{tabular}{|c|c|c|c|c|c|c|c|c|c|c|c|c|}
\hline \multirow[b]{2}{*}{ Criterion } & \multicolumn{3}{|c|}{ CS dependent } & \multicolumn{3}{|c|}{\begin{tabular}{|l} 
Technical \\
parameters
\end{tabular}} & \multicolumn{5}{|c|}{ Economical parameters } & \multirow[b]{2}{*}{$\mathbf{V}_{\mathbf{p}}$} \\
\hline & $\mathbf{A}$ & B & $\mathrm{V}_{\mathbf{C S}}$ & $\mathbf{C}$ & D & $V_{\text {tech }}$ & $\mathbf{E}$ & $\mathbf{F}$ & $\mathbf{G}$ & $\mathbf{H}$ & $\mathbf{V}_{\text {eco }}$ & \\
\hline Weighting coefficient & 10 & 7 & 10 & 7 & 3 & 7 & 10 & 10 & 7 & 1 & 3 & \\
\hline New fish products & 5 & 5 & 1.00 & 5 & 5 & 1.00 & 3 & 5 & 3 & 1 & 0.73 & 0.96 \\
\hline Surimi & 5 & 0 & 0.59 & 3 & 5 & 0.72 & 3 & 3 & 1 & 1 & 0.49 & 0.62 \\
\hline Fish pulp & 5 & 5 & 1.00 & 3 & 5 & 0.72 & 1 & 5 & 5 & 5 & 0.71 & 0.86 \\
\hline Bioactive peptides & 5 & 1 & 0.67 & 3 & 3 & 0.60 & 5 & 3 & 1 & 3 & 0.64 & 0.64 \\
\hline Polyunsaturated fatty acids & 5 & 3 & 0.84 & 3 & 5 & 0.72 & 3 & 5 & 3 & 1 & 0.73 & 0.78 \\
\hline Enzymes & 0 & 0 & 0.00 & 1 & 1 & 0.20 & 1 & 1 & 1 & 1 & 0.20 & 0.10 \\
\hline Chondroitin sulphate & 0 & 3 & 0.25 & 1 & 3 & 0.32 & 5 & 3 & 1 & 1 & 0.63 & 0.33 \\
\hline Fat-soluble vitamins & 5 & 0 & 0.59 & 1 & 3 & 0.32 & 3 & 5 & 1 & 1 & 0.63 & 0.50 \\
\hline Minerals & 5 & 1 & 0.67 & 3 & 5 & 0.72 & 1 & 5 & 5 & 3 & 0.70 & 0.69 \\
\hline Astaxanthin & 0 & 0 & 0.00 & 1 & 5 & 0.44 & 5 & 3 & 1 & 3 & 0.64 & 0.25 \\
\hline Collagen & 5 & 3 & 0.84 & 1 & 5 & 0.44 & 3 & 3 & 3 & 1 & 0.59 & 0.66 \\
\hline Gelatine & 5 & 3 & 0.84 & 1 & 5 & 0.44 & 3 & 3 & 3 & 1 & 0.59 & 0.66 \\
\hline Sterols & 5 & 0 & 0.59 & 1 & 1 & 0.20 & 3 & 3 & 0 & 3 & 0.45 & 0.43 \\
\hline Insulin & 5 & 0 & 0.59 & 3 & 1 & 0.48 & 3 & 1 & 0 & 0 & 0.29 & 0.50 \\
\hline Protamine & 0 & 0 & 0.00 & 1 & 3 & 0.32 & 5 & 1 & 1 & 1 & 0.49 & 0.18 \\
\hline Hyaluronic acid & 0 & 0 & 0.00 & 1 & 3 & 0.32 & 5 & 3 & 1 & 1 & 0.63 & 0.21 \\
\hline Chitin/chitosan & 0 & 0 & 0.00 & 1 & 5 & 0.44 & 5 & 3 & 3 & 1 & 0.73 & 0.26 \\
\hline Phospholipids & 5 & 0 & 0.59 & 1 & 3 & 0.32 & 3 & 3 & 1 & 3 & 0.50 & 0.48 \\
\hline Peptone & 5 & 1 & 0.67 & 3 & 5 & 0.72 & 1 & 1 & 3 & 1 & 0.30 & 0.63 \\
\hline Squalene & 0 & 0 & 0.00 & 1 & 3 & 0.32 & 5 & 3 & 1 & 1 & 0.63 & 0.21 \\
\hline Fishmeal & 5 & 5 & 1.00 & 5 & 5 & 1.00 & 1 & 5 & 5 & 1 & 0.69 & 0.95 \\
\hline Fish oil & 5 & 5 & 1.00 & 5 & 5 & 1.00 & 1 & 5 & 5 & 1 & 0.69 & 0.95 \\
\hline Mink feed & 5 & 3 & 0.84 & 5 & 3 & 0.88 & 1 & 1 & 5 & 3 & 0.41 & 0.79 \\
\hline Marine beef/bait & 5 & 1 & 0.67 & 5 & 3 & 0.88 & 1 & 1 & 5 & 3 & 0.41 & 0.71 \\
\hline Direct pig feed & 5 & 1 & 0.67 & 5 & 3 & 0.88 & 1 & 3 & 5 & 3 & 0.56 & 0.73 \\
\hline Protein concentrate & 5 & 3 & 0.84 & 5 & 5 & 1.00 & 3 & 5 & 3 & 3 & 0.74 & 0.88 \\
\hline Protein hydrolysate & 5 & 3 & 0.84 & 5 & 5 & 1.00 & 3 & 5 & 3 & 3 & 0.74 & 0.88 \\
\hline Silage & 5 & 0 & 0.59 & 5 & 5 & 1.00 & 1 & 3 & 5 & 3 & 0.56 & 0.73 \\
\hline Insect growth & 5 & 0 & 0.59 & 5 & 1 & 0.76 & 1 & 3 & 5 & 5 & 0.57 & 0.65 \\
\hline Leather & 0 & 3 & 0.25 & 1 & 5 & 0.44 & 3 & 1 & 3 & 5 & 0.47 & 0.35 \\
\hline Fish oil & 5 & 5 & 1.00 & 5 & 5 & 1.00 & 0 & 5 & 5 & 0 & 0.61 & 0.94 \\
\hline Minerals & 5 & 3 & 0.84 & 3 & 5 & 0.72 & 0 & 3 & 5 & 3 & 0.49 & 0.74 \\
\hline Chitin / chitosan & 0 & 0 & 0.00 & 3 & 5 & 0.72 & 1 & 3 & 3 & 1 & 0.44 & 0.32 \\
\hline Pearl essence & 5 & 0 & 0.59 & 1 & 5 & 0.44 & 1 & 1 & 3 & 3 & 0.31 & 0.50 \\
\hline Biogas & 5 & 1 & 0.67 & 1 & 3 & 0.32 & 1 & 3 & 3 & 1 & 0.44 & 0.51 \\
\hline Compost & 5 & 1 & 0.67 & 3 & 3 & 0.60 & 0 & 3 & 5 & 1 & 0.47 & 0.62 \\
\hline Fertilisers & 5 & 1 & 0.67 & 3 & 5 & 0.72 & 1 & 3 & 5 & 1 & 0.54 & 0.67 \\
\hline
\end{tabular}

$A$ Available raw material, $B$ Available facilities, $C$ Yield, $D$ Technology maturity, $E$ Value of the product, $F$ Potential market, $G$ Production costs, $H$ Competing companies, $V_{C s}$ : case study score, $V_{\text {tech }}$ technical score, $V_{\text {eco }}$ economic score, $V_{p}$ priority value 


$$
\mathrm{V}_{\mathrm{p}}=\left(\mathrm{y}_{1} \cdot \mathrm{V}_{\mathrm{CS}}+\mathrm{y}_{2} \cdot \mathrm{V}_{\text {tech }}+\mathrm{y}_{3} \cdot \mathrm{V}_{\text {eco }}\right) /\left(\mathrm{y}_{1}+\mathrm{y}_{2}+\mathrm{y}_{3}\right)
$$

Where $\mathrm{y}_{1}$ to $\mathrm{y}_{3}$ are the weighting coefficient values assigned to each category (Table 17.6).

The weighing coefficient value for each prioritisation criterion and category was assigned through consensus within the DiscardLess project expert team. As an example, the availability of raw material (criterion A) was considered a critical factor and was therefore assigned a weighing coefficient value of 10 .

The current values were used considering the present situation where the LO is being implemented, and thus the preferred options are those building on existing infrastructures (high $\mathrm{V}_{\mathrm{cs}}$ weighting coefficient). These coefficients can be changed for a long-term solution by increasing the weighting coefficient of $\mathrm{V}_{\text {eco }}$.

This methodology not only allows simultaneous evaluation of all the criteria but also the technical and economical evaluation of each valorisation option separately, and evaluation of the weight of the case study dependent criteria. However, only a preliminary diagnostic is provided which should be discussed further with stakeholders.

The implementation of any selected valorisation option resulting from this methodology will need a more detailed feasibility study.

In Table 17.6, the example of the prioritisation analysis for a specific case study is presented, i.e. the discards of the Bay of Biscay.

\subsection{Methodology for the Selection of Inland Management Alternatives Based on Economic and Environmental Impacts}

When selecting the optimal processing routes of the different potentially available biomasses in terms of sustainability, both the economic and environmental objectives must be considered simultaneously. A common approach in the scientific literature There is a major tendency in the scientific literature to apply different optimisation strategies to study the trade-off between these two conflicting objectives. The optimisation of processing routes integrating both criteria was for example applied to the case of bio-refineries involving different feedstock types (MartinezHernandez et al. 2013; Murillo-Alvarado et al. 2013; Bernardi et al. 2013; Santibanez-Aguilar et al. 2014; Antelo et al. 2015).

In a second case study below, we define an optimisation screening approach adapted to the particularities of marine biomass discarded in trawling fleets of Galicia (NW Spain) operating in ICES areas VIIIc and IXa. These fleets are characterised by highly mixed catches where determined levels of discards are very significant.

To simplify and systematise the selection of optimal valorisation pathways, we have defined a simplified general network (Fig. 17.3) to represent these valorisation alternatives. In this approach, developed in the framework of the LIFE iSEAS project (LIFE13 ENV/ES/000131), each layer of the above-mentioned 


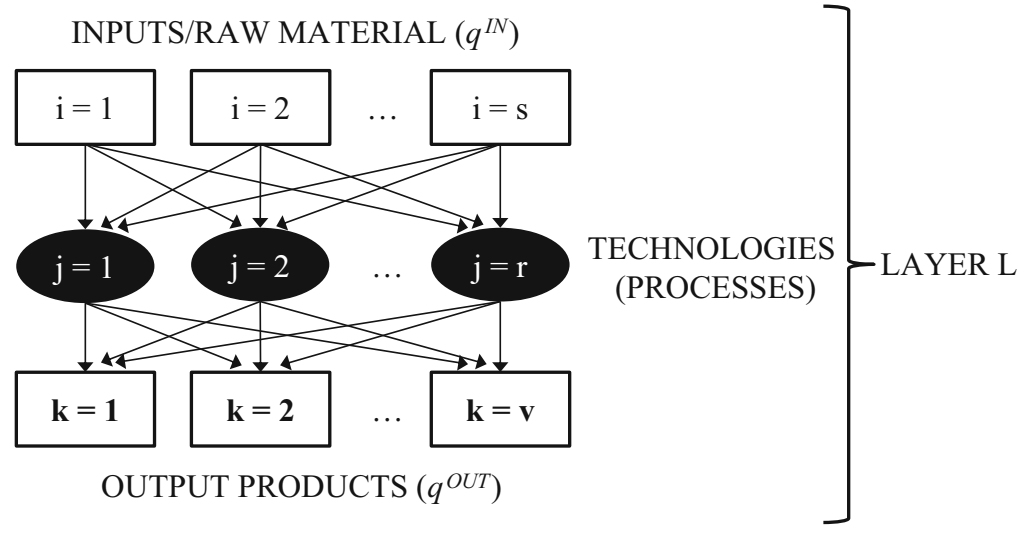

Fig. 17.3 General superstructure of the technology model

superstructure is constituted by $s$ input products (i.e., skins, bones, viscera, muscle, entire specimen, etc. - vector $\boldsymbol{q}^{\boldsymbol{I} N}$ ) that can be processed by a set $r$ of defined processing technologies to obtain $v$ final or output products (i.e., bioactive peptides, fish protein hydrolysates, chitin/chitosan, gelatine, etc.) This formulation allows easy connection of $L$ layers (when further pre-processing or downstream processing is required) by considering the final products of a given layer $l$ the raw material of the next processing network/layer $l+1$. We call this the technology model.

Our case study describes a situation where $100 \%$ of all currently discarded biomass must be landed. Changes in the composition of the considered target fisheries as well as the uncertainties of future legislation might lead to significant variations in the proposed case. In addition, the economic assessment includes costs of the main processing utilities. Water use and $\mathrm{CO}_{2}$ emissions were considered in the environmental assessment. Installation and personnel costs, as well as solid residues derived from processing (considering that these are sent to fish meal production at zero cost), were not included in the analysis. The reason for these assumptions is the increasing complexity of the network and the uncertainty regarding the available data in the case study.

To evaluate the optimal/best pathways for achieving an integral valorisation of discarded biomass in practice, both economic $\left(J_{\text {eco }}\right)$ and environmental $\left(J_{\text {en }}\right)$ objectives are considered and evaluated through a multi-objective approach. The aim is to maximise the economic objectives while minimising environmental impacts.

The $\varepsilon$-constraint approach was used to convert multi-objective problems into a set of single objective problems (by incorporating one of the objectives as an inequality constraint) to obtain uniform distributed Pareto fronts - due to their easy implementation and capability. In this case, we considered that $\varepsilon$ varies between 0 and 700. Computing the Pareto-optimal set can be challenging due to the highly constrained and nonlinear nature of processing systems. This drawback can be addressed by using suitable global optimisation (GO) methods. Therefore, the 
optimal solution of the proposed optimisation problem was calculated using scatter search (eSS) as implemented in the MEIGO toolbox (Egea et al. 2014).

This optimisation problem can be mathematically represented as:

$$
\max _{X} J=J_{\text {eco }}(X)=J_{\text {sales }}(X)-J_{P C}(X)
$$

Subject to:

$$
\begin{gathered}
J_{\text {env }}(X)=\left(J_{\mathrm{CO}_{2}}(X)+J_{w}(X)\right) \leq \varepsilon \\
q^{\text {OUT }}(l+1) \leq M_{o} \quad(\text { Plant capacity }) \\
X^{\text {lower }} \leq X \leq X^{\text {upper }}
\end{gathered}
$$

where $\boldsymbol{X}$ is the decision vector to be found by means of the optimisation problem (in this case, the set of fractions or percentages of raw material $q^{I N}$ processed by a given technology $j$ ) and $\boldsymbol{X}_{\text {lower }}, \boldsymbol{X}_{\text {upper }}$ are the lower and upper bounds for the decision variables, respectively.

The economic part of the objective function represents the profit of the process, which is defined by product sales $\left(J_{\text {sales }}\right)$ minus production costs $\left(J_{P C}\right)$.

The environmental impact of each process was characterised by the ecological footprint $(\mathrm{EF})$. This is an indicator that considers the energy and raw material flow into and out of any particular system, converting them into the spaces of land or water needed by nature to produce and/or assimilate these flows. In this case, environmental criteria for process selection included $\mathrm{CO}_{2}$ emissions (from electricity and fuel consumption $\left.-J_{\mathrm{CO}_{2}}\right)$ and water consumption $\left(J_{w}\right)$. The calculation of EF implies the conversion of units for these flows to space units, usually hectares (ha). For that purpose, values of energy intensity as well as natural and/or energy productivity are required.

The main results show that in general the most optimal processing routes correspond to the production of high value-added products (biopeptides, enzymes and chondroitin sulphate), not only due to high sale prices, but also for the lower environmental impact associated with their production processes as compared to other products (fish meal, fish oil, chitin/chitosan or gelatine). However, chondroitin sulphate production should be considered with caution, as the production obtained was much lower than the plant production capacity. In this case, more biomass (from other fishing métiers or fish-processing industries) would be necessary to guarantee the economic feasibility of the valorisation schemes. Fish meal and fish oil, chitin and gelatine were not preferred, mainly due to the high $\mathrm{CO}_{2}$ emissions and water consumption associated with these processes. 


\subsection{Case Studies}

The selection of potential uses and solutions must be made in each case study. The simplified methodology described is shown for the case studies of Bay of Biscay ( $\mathrm{BoB})$, while the methodology based on economic and environmental parameters is applied to the Galician fleet.

\subsubsection{Basque Fleet in the Bay of Biscay}

The information needed for the application of the simplified methodology for the selection of valorisation options was gathered within the H2020 DiscardLess project. The Bay of Biscay $(\mathrm{BoB})$ is a highly productive fishery zone, in which the Basque fleet operates bottom trawlers (Prellezo et al. 2016).

Data related to main UWC, that represent over the $95 \%$, are presented in Table 17.7.

From these data two problems arise:

1. Mackerel and horse mackerel $>$ MCRS but with low value account for $\sim 2200 \mathrm{t} /$ year. Blue whiting, with an important quantity of $\sim 300 \mathrm{t} / \mathrm{year}$, can be included in this group.

2. Hake $<$ MCRS account for $\sim 300$ t/year

From the study of the infrastructures in the Basque country, there are different facilities that can be of interest for the valorisation of these products:

- The Cofradía (fisher associations) of Bermeo has facilities for fish mince production.

- There are several fish processing industries in the surrounding areas.

- There is a fish by-product valorisation facility that produces fish meal and fish oil.

- In all harbours, freezing facilities are available for conserving UWC.

Table 17.7 Main unwanted catches in the Bay of Biscay bottom-trawl fishery estimation (data 2014)

\begin{tabular}{l|l|l|l|l|l|l|l|l|l}
\hline & \multicolumn{4}{l}{ Discards (t) } & \multicolumn{3}{l|}{ Catch (t) } & \multicolumn{2}{l}{ Landed } \\
\hline Species & 2011 & 2012 & 2013 & 2011 & 2012 & 2013 & 2011 & 2012 & 2013 \\
\hline Anglerfish & 3 & 0 & 5 & 197 & 178 & 254 & 194 & 178 & 249 \\
\hline Black-bellied angler & 11 & 3 & 10 & 147 & 215 & 415 & 136 & 212 & 405 \\
\hline Blue whiting & 117 & 439 & 226 & 250 & 488 & 282 & 133 & 49 & 56 \\
\hline Hake & 217 & 309 & 365 & 2916 & 2401 & 2370 & 2698 & 2092 & 2005 \\
\hline Horse mackerel & 3049 & 2091 & 1467 & 3227 & 2317 & 1618 & 178 & 226 & 151 \\
\hline Mackerel & 3339 & 1620 & 990 & 3728 & 1693 & 1035 & 389 & 73 & 45 \\
\hline Megrim & 5 & 1 & 8 & 176 & 210 & 306 & 170 & 209 & 298 \\
\hline
\end{tabular}


Following the standard methodology for valorisation option selection, discard data were used to obtain scores for criteria A (available raw material) as shown in Table 17.6. Also, the infrastructures available in the Basque Country and surrounding areas were evaluated to complete column B (available facilities).

The valorisation options with the best scores for the main discarded species are:

- Mackerel and horse mackerel study: new food products (96\%) or fish pulp (86\%) have the higher score. This option can also be taken into consideration for blue whiting ( $300 \mathrm{~kg} /$ year $)$ if not $<$ MCRS.

- Due to legislation, hake (<MCRS) cannot be directed to food products so the next options are: fishmeal and fish oil, with a score of $95 \%$ or fish protein hydrolysate, with a score of $88 \%$. This last option could score higher if hydrolysates were focused on human consumption as a flavouring agent.

- This option is also the main possibility when quantities of other UWC are too low for more specific solutions.

As stated above, these results are preliminary. More detailed evaluation of the solution implementation was performed to corroborate their technical and economic viability. Pilot tests for producing a mackerel hamburger and hake FPH were performed to assess the full value chain and verify its profitability. In both processes, the by-products (e.g. bones) were diverted to the fishmeal processing plant in a biorefinery scheme.

\subsubsection{Assays at Pilot Plant Level of Some of the Proposed Alternatives}

The pilot plant studies were developed in the framework of the LIFE iSEAS project. Their aim was to establish a so-called bionode or iDVP (Integral Discards Valorisation Point) that applies a biorefinery concept for this important quantity of marine biomass that has to be managed or processed quickly and efficiently to avoid wasting it. The plant is divided into three rooms: (i) Chilled room storage; (ii) Food processing area (iDVP1, Fig. 17.4 and; (iii) Non-food products area (iDVP3, Fig. 17.5). Production lines to be implemented in the iDVP1 are based on the use of the muscle (fish mince) for food purposes, including a line of restructured products (Fig. 17.6). In addition, the iDVP3 (Fig. 17.5) includes a line for fish protein hydrolysates and bioactive peptides as well as several production lines to obtain valuable bio-compounds such as collagen, chondroitin sulphate or hyaluronic acid, among others (Fig. 17.7). iDVP1 fish by-products and undersized specimens of fish species subject to TAC regulation (mainly hake and megrim) are used as raw material. They may be complemented with industrial by-products such as tuna skins, blue shark skin and head, etc. from fish processors nearby.

The production of fish mince using a fish fraction separator (Fig. 17.4), working with initial loads of 50-100 kg of headless and eviscerated fresh fish per batch, was 


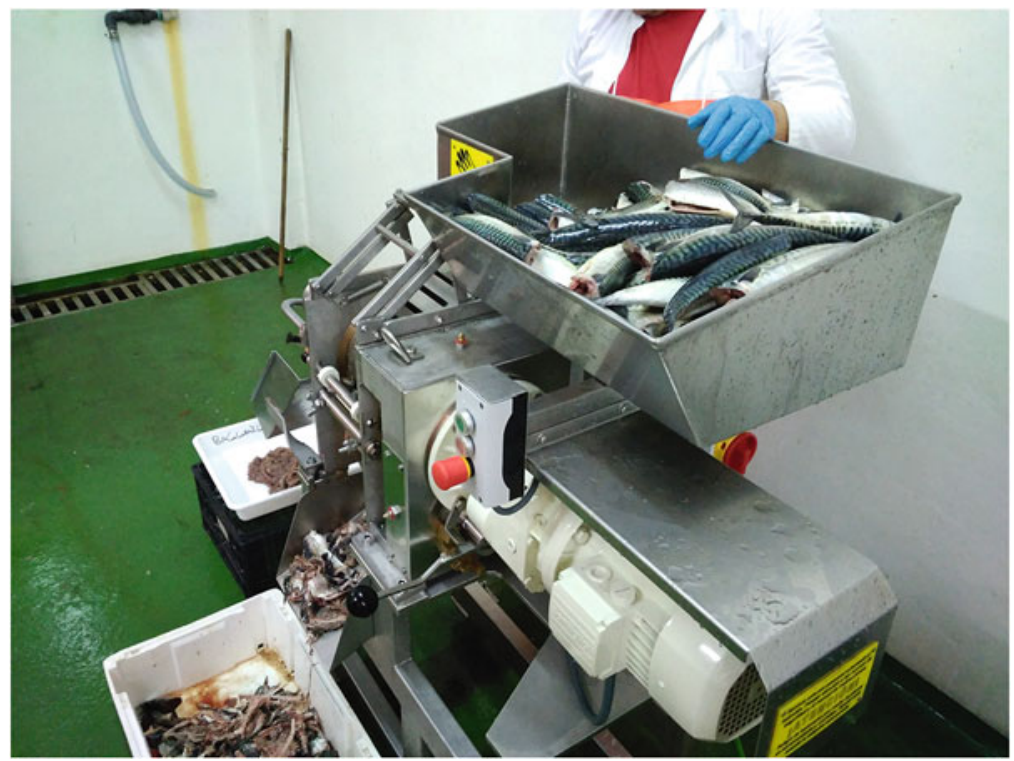

Fig. 17.4 iDVP1 fish fractions separator

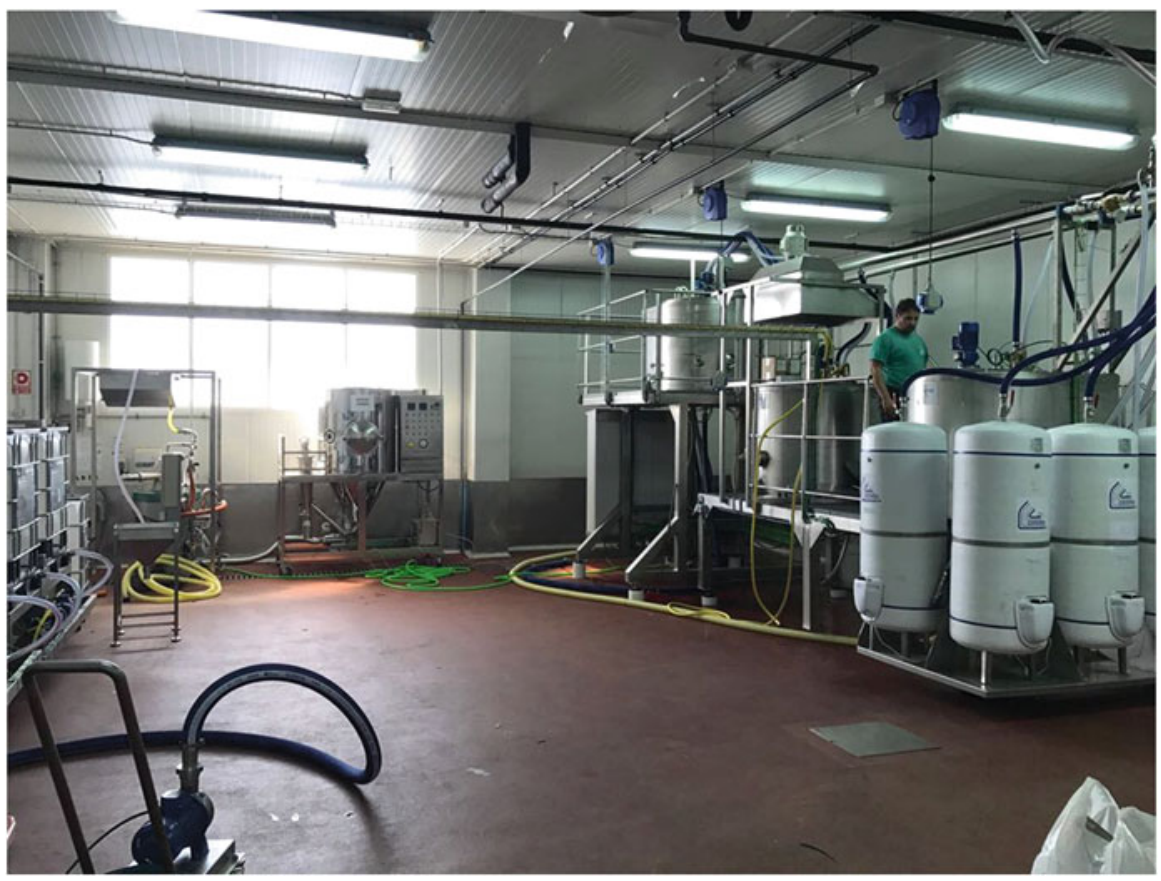

Fig. 17.5 iDVP3 located in the Port of Marín (Spain) 


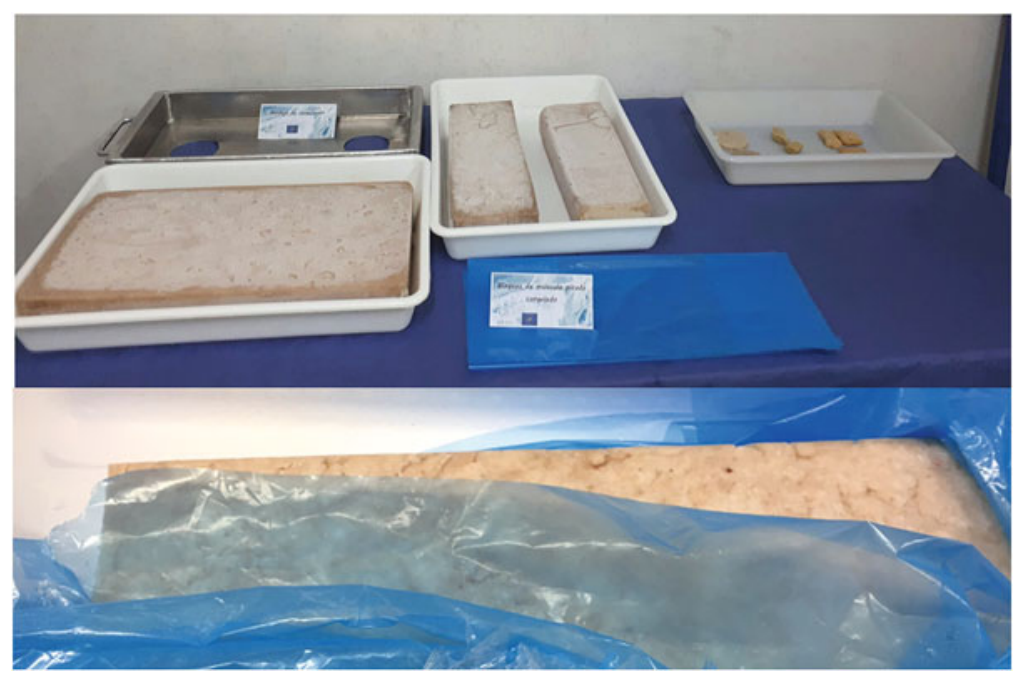

Fig. 17.6 Fish mince blocks obtained in the iDVP1

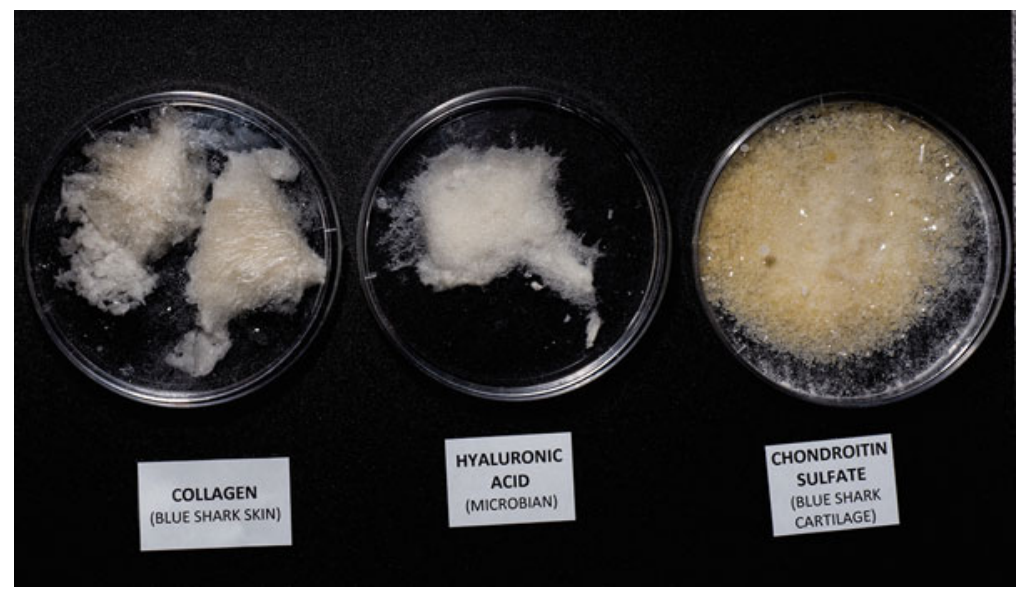

Fig. 17.7 Biocompounds obtained in the iDVP3

successful for all the discards evaluated: pouting, mackerel, sea robins, grenadier, blue whiting, hake, red scorpion fish, etc. Yields and chemical properties of fish mince blocks (Fig. 17.6) were extensively reported (Blanco et al. 2018). The rest of the heads and skin/bones were then processed in iDVP3. Different processed and restructured foods (burgers, nuggets and fingers) were formulated and satisfactorily tested on various tasting days organised for the food industry. The response of diners to the panels of evaluation (scoring the organoleptic, taste and presentation features) was always 'good' or 'excellent' for all the products prepared. 


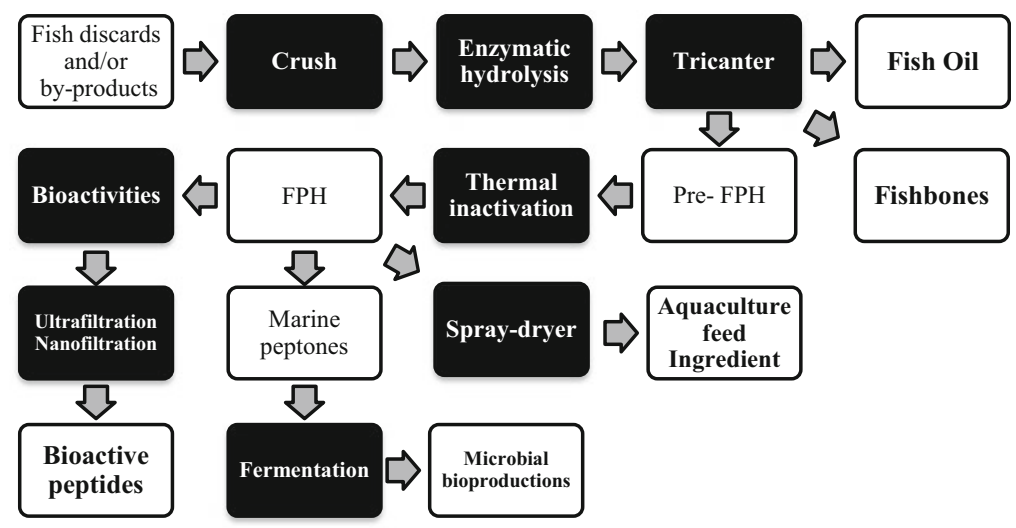

Fig. 17.8 Simplified scheme of fish protein hydrolysates (FPH) process

Another process studied was the production of fish protein hydrolysates (FPH) generated by commercial proteolytic enzymes (alcalase or esperase) using whole fish or by-products from discards (heads and skin/bones). Initially, batch enzyme proteolysis was performed in $5 \mathrm{~L}$ vessels and was subsequently validated in $500 \mathrm{~L}$ pilot plant reactors (iDVP3). The scheme of FPH-production is shown in Fig. 17.8. Unpublished results indicated that in all substrates hydrolysis (digestion of organic material) was complete. Bioactivities of peptides (anti-oxidant and antihypertensive) were analysed and the potential application of FPH as marine peptones for the formulation of low-cost media for microbial bioproduction is currently being evaluated. In the case of fatty fish species, fish oil was recovered from liquid FPH by centrifugation using a tricanter and the fatty acid profiles were determined. In addition, the chemical characterisation and application of mineral fraction obtained (clean fish bones) are also being studied.

Processes for production of other high-added value biocompounds from fish discards and fishing by-products were optimised at a laboratory (1 to $5 \mathrm{~L}$ per batch) and then tested at a pilot plant (iDVP3). The isolation of glycosaminoglycans, such as hyaluronic acid (AH) from fish vitreous humour and chondroitin sulphate (CS) from fish cartilage was done using materials from the eyes of tuna, blue shark and swordfish and cartilage from catshark, blue shark and ray. In both cases, the steps to produce those polysaccharides are generally based on the combination of enzymatic proteolysis, protein electrodeposition, chemical selective precipitation and re-dissolution of carbohydrates, membrane purification and drying (Murado et al. 2012; Blanco et al. 2015; Murado et al. 2010; Vázquez et al. 2016). Despite these efforts, the yields of hyaluronic acid from vitreous humour are lower than those observed by fermentation with Streptococcus zooepidemicus bacteria (Vázquez et al. 2010). Condroitin sulphate was obtained from catsharks (Scyliorhinus canicula) discarded by Galician fishing fleet. These were processed in iDVP3 (50 kg of cartilaginous material). Chondroitin sulphate from the heads of blue shark (Prionace glauca) and head-skeletons of ray (Raja clavata) was also successfully produced at 
pilot plant scale (loads of 40-60 kg). The resulting tailored and well-characterised glycosaminoglycans are in most cases non-existent in the chemical and clinical product market. This successful trial has led to a large number of collaborative projects with Spanish and foreign universities (IBEROS, BLUEHUMAN and CVMar+I) for the formulation of micro and nanodevices for tissue engineering and biosensor applications (Novoa-Carballal et al. 2017; Valcarcel et al. 2017; Ferreira et al. 2018).

Regarding the purification of gelatins, skins of several fish discards (pouting, mackerel, etc.) have been studied. Following an optimised set of stages based on different washes in acid and alkaline solutions, thermal extraction, adsorbent and membrane purification and final drying (Sousa et al. 2017), the extractive yields were low and not very satisfactory. Moreover, the strength of the gelatins was not remarkable. Only the skins of catsharks led to acceptable yield and viscosity values. However, skins obtained from processing fish by-products such as tuna (Thunnus albacares) and blue shark proved to be the best materials to produce high strength gelatine, pure collagen and derivatives (Blanco et al. 2017). Productions at pilot plant volume (50-100 kg of substrates) improved upon yields observed at lab scale $(1-3 \mathrm{~kg})$. Potential applications for our gelatins in the formulation of different foods and tissue regenerative biomaterials is currently under study.

Finally, the production of chitin and subsequent deacetylation to chitosan was optimised using two types of substrates: crustacean exoskeletons (Vázquez et al. 2017a) and squid gladius (pens) (Vázquez et al. 2017b). In the first case, enzymatic deproteinisation, acid demineralisation, alkaline hydrolysis and thermal/alkaline deacetylation were sequentially performed obtaining chitosan with more than $90 \%$ deacetylation degree (DD). The validation of this methodology at the pilot plant was tested on crab (Polybius henslowii) discards. In the second approach, endoskeletons by-products from Illex argentinus were valorised in a simplified protocol combining deproteinisation using proteases and deacetylation by alkaline solutions at high temperature. High purity chitosans (DD > 93\%) with molecular weights (143-339 $\mathrm{kDa})$ were produced. In general, the proposals of valorisation developed in IIM-CSIC were validated using iDPV1 and iDPV3 equipment. A schematic view of the biocompounds generated in iDVP3 plant is displayed in Fig. 17.8. Energy and mass flows calculations, LCA and process integration lines studies will complete these results to optimise our flexible and integral multipurpose pilot plant under the concept of Integral Marine Biorefinery.

\subsection{Conclusions}

Unwanted catches can be valorised in many different ways, depending on their composition. Not all of those ways are always feasible, however. A well-structured systematic methodology is therefore needed to help choose the best potential valorisation route. A first approach, based on a multi-criteria decision analysis (MCDA) using an analytic hierarchy process (AHP) method, was applied to the 
case of the Basque fleet in the Bay of Biscay. The best options identified for these discarded species were new fish products based on fish mince; fishmeal and oil; and protein hydrolysates. A second approach, based on the analysis and optimization of economic and environmental parameters, was applied to the highly mixed discards of the Galician fleet. Here, the preferred options were fish mince blocks, protein hydrolysates with bioactive peptides and chondroitin sulphate. For both approaches, pilot trials were performed to demonstrate their feasibility. The good results obtained in both cases indicate that both methodologies can be useful when developing valorisation strategies for UWC in other regions.

Acknowledgments DiscardLess project has received funding from the European Union's Horizon 2020 Framework Programme for Research and Innovation under grant agreement no. 633680. Life iSEAS has been co-funded under the LIFE+Environment Program of the European Union (LIFE13 ENV/ES/000131).

\section{References}

Antelo, L.T., De Hijas-Liste, G.M., Franco-Uría, A., Alonso, A.A., Pérez-Martín, R.I. (2015). Optimisation of processing routes for a marine biorefinery. Journal of Cleaner Production, 104, 489-501. https://doi.org/10.1016/j.jclepro.2015.04.105.

Bernardi, A., Giarola, S., Bezzo, F. (2013). Spatially explicit multiobjective optimization for the strategic design of first and second generation biorefineries including carbon and water footprints. Industrial and Engineering Chemistry Research, 52(22), 7170-80. https://doi.org/10. 1021/ie302442j.

Blanco, M., Fraguas, J., Sotelo, C.G., Pérez-Martín, R.I., Vázquez, J.A. (2015). Production of chondroitin sulphate from head, skeleton and fins of Scyliorhinus canicula by-products by combination of enzymatic, chemical precipitation and ultrafiltration methodologies. Marine Drugs, 13, 3287-3308.

Blanco, M., Vázquez, J.A., Sotelo, C.G., Pérez-Martín, R.I. (2017). Hydrolysates of fish skin collagen: An opportunity for valorizing fish industry byproducts. Marine Drugs, 15, 131.

Blanco, M., Domínguez-Timón, F., Pérez-Martín, R.I., Fraguas, J., Ramos-Ariza, P., Vázquez, J. A., Borderías, A.J., Moreno, H.M. (2018). Under evaluation. Valorization of recurrently discarded fish species in trawler fisheries in North-West Spain. Journal of Food Science and Technology.

Egea, J.A., Henriques D., Cokelaer, T., Villaverde, A.F., MacNamara, A., Danciu, D.P, Banga, J. R., Saez-Rodriguez, J. (2014). MEIGO: An open-source software suite based on metaheuristics for global optimization in systems biology and bioinformatics. BMC Bioinformatics, 15(1), 136. https://doi.org/10.1186/1471-2105-15-136.

European Parliament Council, 2008/98/EC of The European Parliament and of the Council of 19 November 2008 on waste and repealing certain Directives. 2008. Brussels.

FAO. (2017). FAO yearbook. Fishery and Aquaculture Statistics. 2015/FAO annuaire. Statistiques des pêches et de l'aquaculture. 2015/FAO anuario. Estadísticas de pesca y acuicultura. 2015. Rome/Roma, Italy/Italie/Italia.

Ferreira, V.R.A., Azenha, M.A., Mêna, M.T., Moura, C., Pereira, C.M., Pérez-Martín, R.I., Vázquez, J.A., Silva, A.F. (2018). Cationic imprinting of Pb (II) within composite networks based on bovine or fish chondroitin sulfate. Journal of Molecular Recognition, 31(3), e2614.

Froese, R., \& Pauly, D. (Eds.). (2018). FishBase. www.fishbase.org, version (02/2018). 
Iñarra, B., Bald, C., Cebrián, M., Pérez-Villareal, B., Zufía, J. (2018) Guide for the selection of valorisation options of by-catches. Derio: AZTI. ISBN: 978-84-944022-4-1

Martinez-Hernandez, E., Campbell, G., Sadhukhan, J. (2013). "Economic value and environmental impact (EVEI) analysis of biorefinery systems." Chemical Engineering Research and Design, 91(8), 1418-26. https://doi.org/10.1016/j.cherd.2013.02.025.

Murado, M.A., Fraguas, J., Montemayor, M.I., Vázquez, J.A., González, P. (2010). Preparation of highly purified chondroitin sulphate from skate (Raja clavata) cartilage by-products. Process optimization including a new procedure of alkaline hydroalcoholic hydrolysis. Biochemical Engineering Journal, 49, 126-132.

Murado, M.A., Montemayor, M.I., Cabo, M.L., Vázquez, J.A., González, M.P. (2012). Optimization of extraction and purification process of hyaluronic acid from fish eyeball. Food and Bioproducts Processing, 90, 491-498.

Murillo-Alvarado, P.E., Ponce-Ortega, J.M., Serna-González, M., Castro-Montoya, A.J., El-Halwagi, M.M. (2013). Optimization of pathways for biorefineries involving the selection of feedstocks, products, and processing steps. Industrial and Engineering Chemistry Research, 52(14), 5177-90. https://doi.org/10.1021/ie303428v.

Novoa-Carballal, R., Pérez-Martín, R., Blanco, M., Sotelo, C.G., Fassini, D., Nunes, C., Coimbra, M.A., Silva, T.H., Reis, R.L., Vázquez, J.A. (2017). By-products of Scyliorhinus canicula, Prionace glauca and Raja clavata: A valuable source of predominantly 6S sulphated chondroitin sulphate. Carbohydrate Polymers, 157, 31-37.

O’Neil, F.G., Feekings, J., Fryer, R.J., Fauconnet, L., Afonso, P. (this volume). Discard avoidance by improving fishing gear selectivity: Helping the industry help themselves. In S.S. Uhlmann, C. Ulrich, S.J. Kennelly (Eds.), The European discard policy - Reducing unwanted catches in complex multi-species and multi-jurisdictional fisheries. Cham: Springer.

Prellezo, R., Carmona, I. García, D. (2016). The bad, the good and the very good of the landing obligation implementation in the Bay of Biscay: A case study of Basque trawlers. Fisheries Research, 181, 172-185.

Reid, D.G., Calderwood, J., Afonso, P., Bourdeau, P., Fauconnet, L., et al. (this volume). The best way to reduce discards is by not catching them! In S.S. Uhlmann, C. Ulrich, S.J. Kennelly (Eds.), The European discard policy - Reducing un-wanted catches in complex multi-species and multi-jurisdictional fisheries. Cham: Springer.

San Martin, D., Orive, M., Martínez, E., Iñarra, B., Ramos, S., González, N., Guinea de Salas, A., Vázquez, L., Zufía, J. (2017). Decision making supporting tool combining AHP method with GIS for implementing food waste valorisation strategies. Waste and Biomass Valoriztion, 8, $1555-1567$.

Santibañez-Aguilar, J.E., González-Campos, J.B., Ponce-Ortega, J.M., Serna-González, M., El-Halwagi, M.M. 2014. Optimal planning and site selection for distributed multiproduct biorefineries involving economic, environmental and social objectives. Journal of Cleaner Production, 65(15), 270-294.

Sousa, S.C., Vázquez, J.A., Pérez-Martín, R.I., Carvalho, A.P., Gomes, A.M. (2017). Valorization of by-products from commercial fish species: Extraction and chemical properties of skin gelatins. Molecules, 22, 1545.

Valcarcel, J., Novoa-Carballal, R., Pérez-Martín, R.I., Reis, R.L., Vázquez, J.A. (2017). Glycosaminoglycans from marine sources as therapeutic agents. Biotechnology Advances, 35, $711-725$.

Vázquez, J.A., Montemayor, M.I., Fraguas, J., Murado, M.A. (2010). Hyaluronic acid production by Streptococcus zooepidemicus in marine by-products media from mussel processing wastewaters and tuna peptone viscera. Microbial Cell Factories, 9(1), 46.

Vázquez, J.A., Blanco, M., Fraguas, J., Pastrana, L., Pérez-Martín, R.I. (2016). Optimisation of the extraction and purification of chondroitin sulphate from head by-products of Prionace glauca by environmental friendly processes. Food Chemistry, 198, 28-35.

Vázquez, J.A., Ramos, P., Mirón, J., Valcarcel, J., Sotelo, C.G., Pérez-Martín, R.I. (2017a). Production of chitin from Penaeus vannamei by-products to pilot plant scale using a 
combination of enzymatic and chemical processes and subsequent optimization of the chemical production of chitosan by response surface methodology. Marine Drugs, 15, 180.

Vázquez, J.A., Noriega, D., Ramos, P., Valcarcel, J., Novoa-Carballal, R., Pastrana, L., Reis, R.L., Pérez-Martín, R.I. (2017b). Optimization of high purity chitin and chitosan production from Illex argentinus pens by a combination of enzymatic and chemical processes. Carbohydrate Polymers, 174, 262-272.

Open Access This chapter is licensed under the terms of the Creative Commons Attribution 4.0 International License (http://creativecommons.org/licenses/by/4.0/), which permits use, sharing, adaptation, distribution and reproduction in any medium or format, as long as you give appropriate credit to the original author(s) and the source, provide a link to the Creative Commons license and indicate if changes were made.

The images or other third party material in this chapter are included in the chapter's Creative Commons license, unless indicated otherwise in a credit line to the material. If material is not included in the chapter's Creative Commons license and your intended use is not permitted by statutory regulation or exceeds the permitted use, you will need to obtain permission directly from the copyright holder. 